\title{
ARTICLE
}

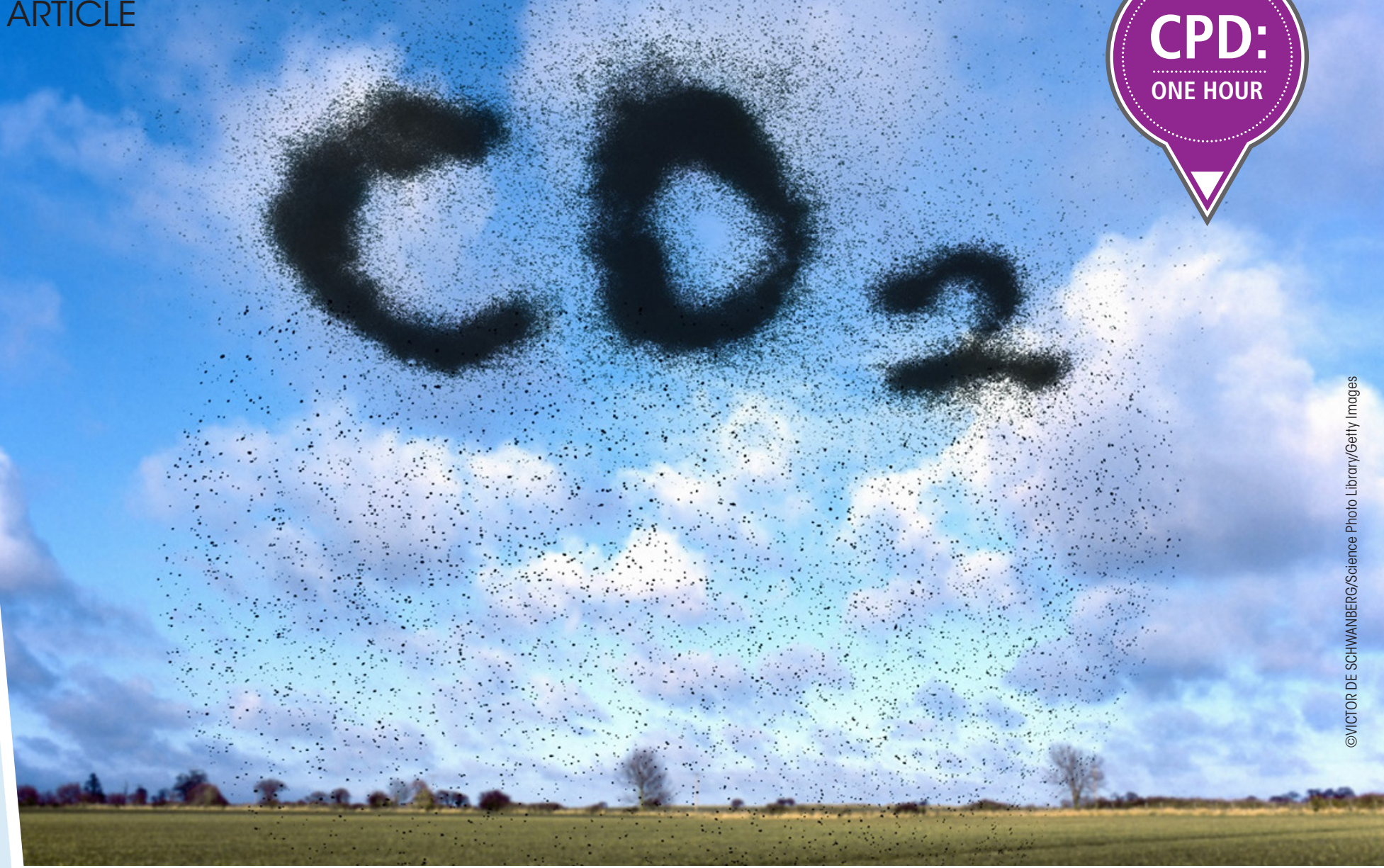

\section{What's in a bin?}

\section{A case study of dental clinical waste composition and potential}

greenhouse gas emission savings, by J. Richardson, ${ }^{1}$ J. Grose, ${ }^{2}$ S. Manzi, ${ }^{3}$ I. Mills, ${ }^{4}$ D. R. Moles, ${ }^{5}$ R. Mukonoweshuro, ${ }^{6}$ M. Nasser ${ }^{7}$ and A. Nichols. ${ }^{8}$

\section{Introduction}

The impact of high levels of carbon on the environment has been well documented. ${ }^{1,2}$ Healthcare services are responsible for a significant percentage of these emissions ${ }^{3}$ and need to review where services and activities can make reductions. Due to relatively large carbon dioxide (CO2) emissions, the use of toxic materials and the production of vast amounts of waste, healthcare is compromising public health and damaging the ability of future generations to meet their needs. ${ }^{4}$ In the EU, the health sector creates at least $5 \%$ of total $\mathrm{CO} 2$ emissions. $^{5}$ Furthermore, improving energy and resource efficiency and the development of sustainable procurement policies and waste management are vital for the health sector. ${ }^{3}$ Although a small number of studies of waste management have been conducted in health and social care waste management, ${ }^{6-10}$ studies on waste management in dentistry are limited. Of equal concern is the variety of materials used in healthcare and dentistry (for example, plastics, cotton and rare metals) that are subject to the influences of climate change and geopolitical unrest. ${ }^{11-13}$ Since 2009 a number of guidance documents have been developed which enable health service providers to begin to embed sustainability principles into policy and practice. ${ }^{2,14}$ The NHS has begun to reduce carbon output while at the same time managing to increase productivity. ${ }^{15}$ There is still a long way to go to embed sustainability across all departments and to ensure that items used in healthcare come from sustainable sources. Items should be purchased with reuse in mind and methods of disposal chosen with environmental protection as a core purpose. As the climate changes and affects accessibility to some raw materials, prices of these raw materials will rise and choices will need to be made about what is essential and whether or not alternatives can be found. Furthermore, to reduce the impact of carbon produced from long supply chains, the manufacture and disposal of items used in healthcare will need to be closer to the end user. 


\section{Rationale}

Although there are a number of articles exploring the quality and quantity of waste in dental practices, there are no studies on organisational, educational or behavioural strategies to decrease unnecessary waste. ${ }^{16}$ Dental practices have a unique position as staff use a high number of dental materials and instruments on a daily basis (unlike medical practices). It is unclear how dentists' and dental care professionals' (DCPs') choices and behaviours around selecting and using materials impact on the amount of unnecessary waste production. Much of the current environmental discussion in dentistry is focused around the use and disposal of dental amalgam, and several European countries have banned its use due to the negative environmental impact. This may be a highly relevant issue, but it would appear to have deflected the focus from other environmental considerations including the impact of clinical waste management in dental practices.

Farmer et al. ${ }^{17}$ undertook a waste audit of dental practices in Australia and reported that materials used to support infection control constituted up to $91 \%$ of total waste produced. Although individual dentists generate a relatively small amount of environmentally unfriendly wastes, the accumulated waste produced by the profession may have a significant environmental impact. Dental waste not only has negative effects on the environment, but the cost of its removal falls heavily on dental practice budgets. In 2009 new infection control guidance was introduced within England and Wales (Scottish guidance contains variations) under the Health Technical Memorandum HTM 01-05. ${ }^{18}$ This was subsequently revised in 2013. This has impacted significantly on dental practices and is considered to have had a deleterious effect on environmental sustainability in dentistry.

This study seeks to investigate clinical waste production in a single dental practice as a case study, building on the evidence gap by using methods previously developed through healthcare waste and procurement studies $s^{9,10,12,19}$ and the rapid evidence review undertaken by Nasser. ${ }^{16}$

\section{AIM}

This study aims to measure the nature and quantity of clinical dental waste, and assess the feasibility of measuring the potential financial and carbon savings of appropriate segregation and recycling.

\section{OBJECTIVES}

1. To measure the nature and quantity of clinical dental waste

THE WASTE PRODUCED BY THE PROFESSION MAY

HAVE A SIGNIFICANT ENVIRONMENTAL IMPACT.'

2. To assess the feasibility of measuring the financial cost of dental clinical waste

3. To measure the extent to which waste is incorrectly segregated in order to estimate the potential greenhouse gas (GHG) savings that might be achieved through better waste management.

\section{METHODS}

\section{Rationale for data} collection process:

Evidence suggests that inappropriate healthcare waste segregation can lead to nonclinical waste being disposed of in the clinical waste stream. ${ }^{17}$ The consequence of this is the unnecessary incineration of non-clinical waste at high financial cost and excessive GHG emissions. In order to examine the extent of non-clinical waste being allocated to the clinical waste stream an audit approach was designed to weigh and categorise the clinical waste of one dental practice. The audit approach used in this study has been tested in recent research by the Sustainability Society and Health Research Group (SSHRG) at Plymouth University in a study of waste management in health and social care in Cornwall. ${ }^{10,19}$

\section{Sample}

The site for the study was a mixed NHS/ private dental practice in North Devon. The clinical waste generated during treatment sessions over a specified period in this practice was audited by the research team.

\section{Data collection}

Clinical waste at the study practice is collected weekly by a waste management company and collection is always scheduled for a Friday. A decision was made to carry out the waste audit on two separate occasions: Thursday, 28 August 2014 (session 1) and Wednesday, 10 September (session 2). This would ensure that a sufficiently large amount of waste was available from which to select a sample. In addition to examining the contents of the waste bags from the two data collection sessions, the total clinical waste for session 2 was weighed to provide an estimate of the mass of waste produced. Since the waste that was weighed on session 2 had accumulated over a four day period, its mass was inflated by a factor of $25 \%$ in the analyses in order to estimate the amount of waste produced in a working week (five days). Waste was recorded and classified according to the type of material and the frequency with which it was found. A range of the most common items used in each treatment session was photographed. Each item was identified, weighed, and the amount of waste recorded (frequency and mass).

\section{Minimising the risk of bias}

The clinical waste audit was conducted on days of the week shortly before collection was due, and on two occasions separated by a five week interval. This allowed for some variation in clinicians and in working practices and treatments. Ultimately, the focus of the study is the use and disposal of dental consumables and not an examination of treatment so the potential for bias is reduced. All data entry has been quality assured by: (i) a sample of quantitative data entry that was audited by a member of the audit team not involved in entry; (ii) an audit trail that has been kept for all aspects of the project.

\section{Ethical approval safety and study conduct in relation to normal working of the practice \\ Activities took place using the code of practice for research developed through Plymouth University's Faculty of Health and Human Sciences Research Ethics Committee. All data collected were anonymised to protect the participants and maintain confidentiality.}

\begin{tabular}{|c|c|}
\hline Clinical waste items & Variable \\
\hline Sterile wrapping & $\begin{array}{l}\text { Recyclable waste variable (IVI): } \\
\text { Within each dental clinical waste bag } \\
\text { (Percentage of [mass of recyclable clinical waste items per / total mass per bag]) }\end{array}$ \\
\hline $\begin{array}{l}\text { Tissues, gloves, bibs, } 3 \text { in } 1 \\
\text { tips, other clinical items }\end{array}$ & $\begin{array}{l}\text { Non-recyclable waste variable (IV2): } \\
\text { Within each dental clinical waste bag } \\
\text { (Percentage of [mass of non-recyclable waste items per bag / total mass per bag]) }\end{array}$ \\
\hline
\end{tabular}


Patients were aware of a researcher in the building. The practice used an electronic notice board and information about the study was made available as part of the daily notices. A reflective log noting any issues that impact on study design or practical issues of data collection was maintained throughout the study period. This was used to make any necessary revisions to inform a possible larger study involving diverse dental practices. Relevant and appropriate protective clothing and face shields were used during the data collection process.

\section{Data analysis}

Descriptive statistics describing the composition of the clinical waste at the participating dental practice were obtained from the raw data using the statistics package SPSS version 21 . Further analyses were undertaken to explore whether simple linear relationships exist between the possible recyclable waste (sterile wrapping packaging) and the total mass of waste within each dental clinical waste bag. In order to undertake this linear regression analysis, the data for each clinical waste bag were uploaded onto Microsoft Excel. The clinical wastes of these bags were divided into two groups namely recyclable waste (sterile wrapping packaging) and the non-recyclable waste (all other clinical waste items). These data formed the independent variables respectively of the simple regression analysis as reflected in Table 1. The ' $\mathrm{Y}$ ' variable of the simple linear regression analysis were the natural logarithm of the total mass of each dental clinical waste bag recorded during the dental waste audit by this research study and of each simulated clinical waste bag. The identified coefficients associated with the recyclable and nonrecyclable waste within the dental clinical waste bags indicate whether there are any minimum immediate potential financial cost savings (recyclable waste) that can be made on dental clinical waste disposal.

\section{RESULTS}

The summary composition of waste bags from the clinical waste stream at the participating dental practice is described in Table 2.

Waste bags contained a median of 25 different types of item and a median of 174.50 items in total. Items were composed of seven different materials and each bag had a mean weight mass of $0.6724 \mathrm{~g}$

The most frequently disposed of items during clinic sessions can be seen in Figure 1 . Tissues were the most frequently found item in the clinical waste. Gloves were the second most frequently disposed of item during

\begin{tabular}{|c|c|c|c|c|c|c|}
\hline & Minimum & Maximum & $\begin{array}{c}\text { Sum } \\
\text { (10 bags) }\end{array}$ & Median & Mean & SD \\
\hline Unique items & 6 & 28 & 206 & 25 & 20.60 & 7.95 \\
\hline Item frequency & 44 & 286 & 1841 & 174.5 & 184.10 & 78.11 \\
\hline Materials & 4 & 10 & 67 & 7 & 6.70 & 1.70 \\
\hline Mass (g) & 150 & 1270 & 6720 & 6118 & 672.4 & 322.6 \\
\hline
\end{tabular}

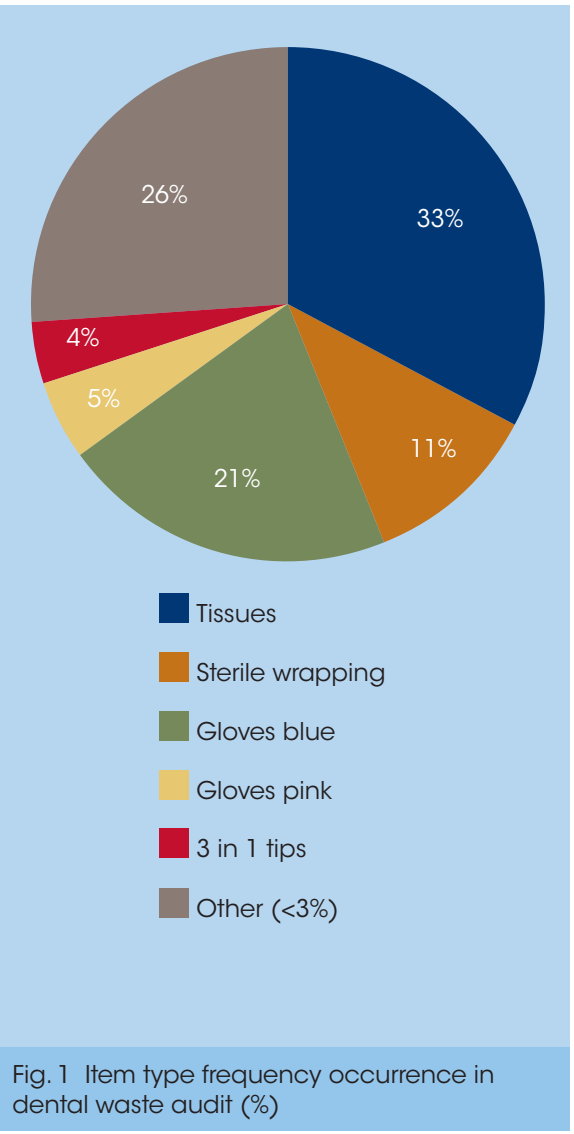

dental clinic sessions; the different colours of gloves reflect size and were analysed separately due to their different weights. The sterile wrapping, in which re-usable dental instruments were brought to the treatment

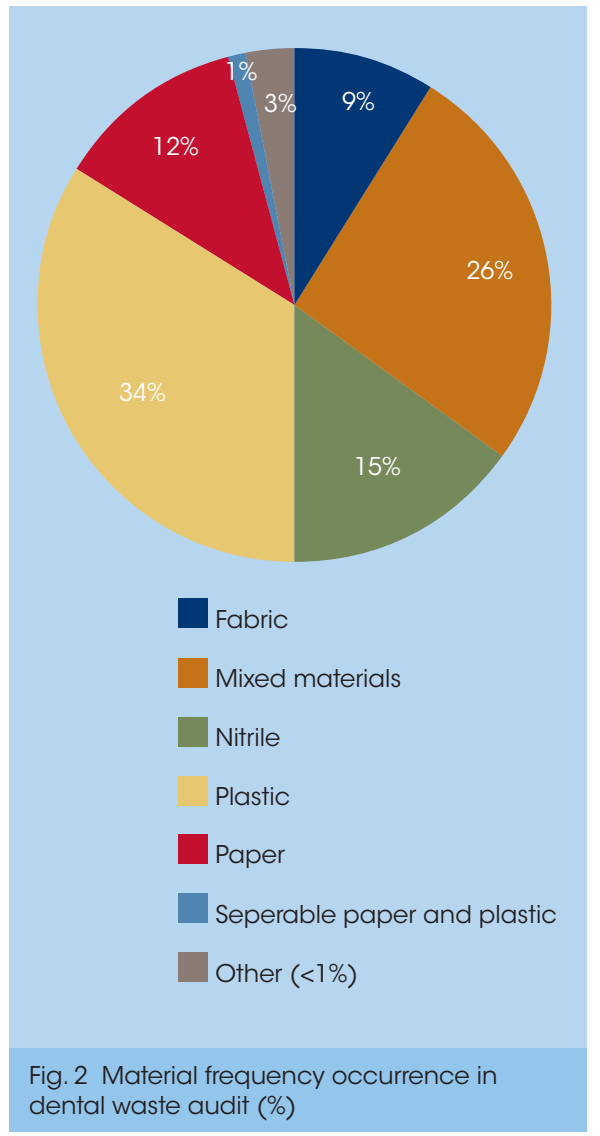

rooms post sterilisation and before use, were the third most frequently disposed of item type.

Figure 2 shows that paper comprised the most frequent material proportion of waste

\begin{tabular}{|c|c|c|c|c|c|}
\hline Model & Constant & $\begin{array}{c}\text { Recyclable } \\
\text { waste }\end{array}$ & $\begin{array}{c}\text { Non- } \\
\text { recyclable } \\
\text { waste }\end{array}$ & ADJ $R^{2}$ & F-STAT \\
\hline Simple linear regression model: 1 & $1.209^{* * *}$ & $-0.012 * * *$ & & 0.684 & 1082.530 \\
\hline Simple linear regression model: 2 & $1.058^{*}$ & & $0.013^{* * *}$ & 0.706 & 1197.4 \\
\hline \multicolumn{6}{|c|}{ 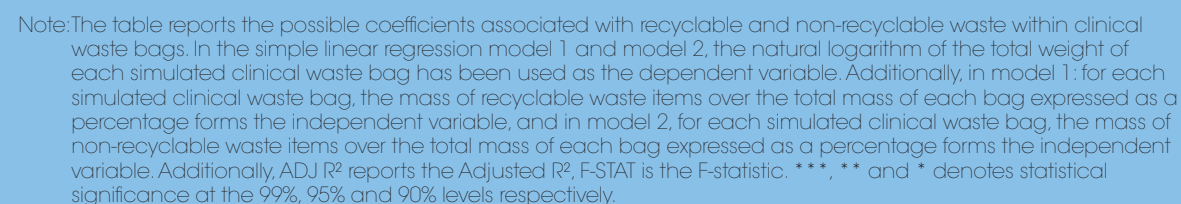 } \\
\hline
\end{tabular}


from the dental clinic sessions. The material nitrile, from which the gloves are made, was the second most frequently disposed of material. Plastic was the third most frequently disposed of material. The sterile wrapping, which was the third most commonly disposed of item, was comprised of separable paper and plastic material components. Separable paper and plastic was the fourth most frequently disposed of material type.

The total mass of items disposed of during the dental clinic sessions sampled can be seen in Figure 3. Almost 3,000 g of the total 6,720 g waste audited was tissues, and almost $1,800 \mathrm{~g}$ of waste was comprised of nitrile gloves (blue and pink). Overall the third heaviest material type was the sterile wrapping.

Figure 4 shows that paper constituted over $3,000 \mathrm{~g}$ of the total audited waste and Nitrile waste had the second highest overall mass $(1,800$ g). Mixed materials, plastic and separable paper and plastic material types all had similar overall masses of just over $500 \mathrm{~g}$ each.

The findings of the waste audit showed that the most common items in dental waste by frequency were also the most frequent items by mass. The material type frequency and mass findings were similarly consistent. The item type and material type findings were also fairly consistent with each other. Paper tissues and nitrile gloves were the two most commonly disposed of item and material types during dental clinic sessions.

Sterile wrapping was the third most frequently disposed of waste item. Although by weight sterile wrapping only contributed less than one third of the mass that nitrile gloves did, it is a highly recyclable piece of waste. More effective separation of sterile wrapping (for recycling) before it comes into contact with any form of contamination could potentially reduce waste amounts by up to 5 $\mathrm{kg}$ per week at this practice.

Table 3 shows that at $99 \%$ significant level, the weights of the recyclable waste (weight of sterile wrapping) have a negative linear relationship to the total mass of the clinical waste bags. The negative linear relationship is due to the fluctuations that exist in the weights of sterile wrapping within the clinical waste bags. The sterile wrapping fluctuates between $5 \%$ and $10 \%$ per waste bag, depending on the quantity of sterile wrapping disposed of by the dental practice during the given time period. The masses of the recyclable clinical waste (for example, mass of sterile wrapping), indicate where potential immediate minimum financial cost savings can be realised by the dental practice when, for example, sterile wrappings are not included within the dental clinical waste bags.
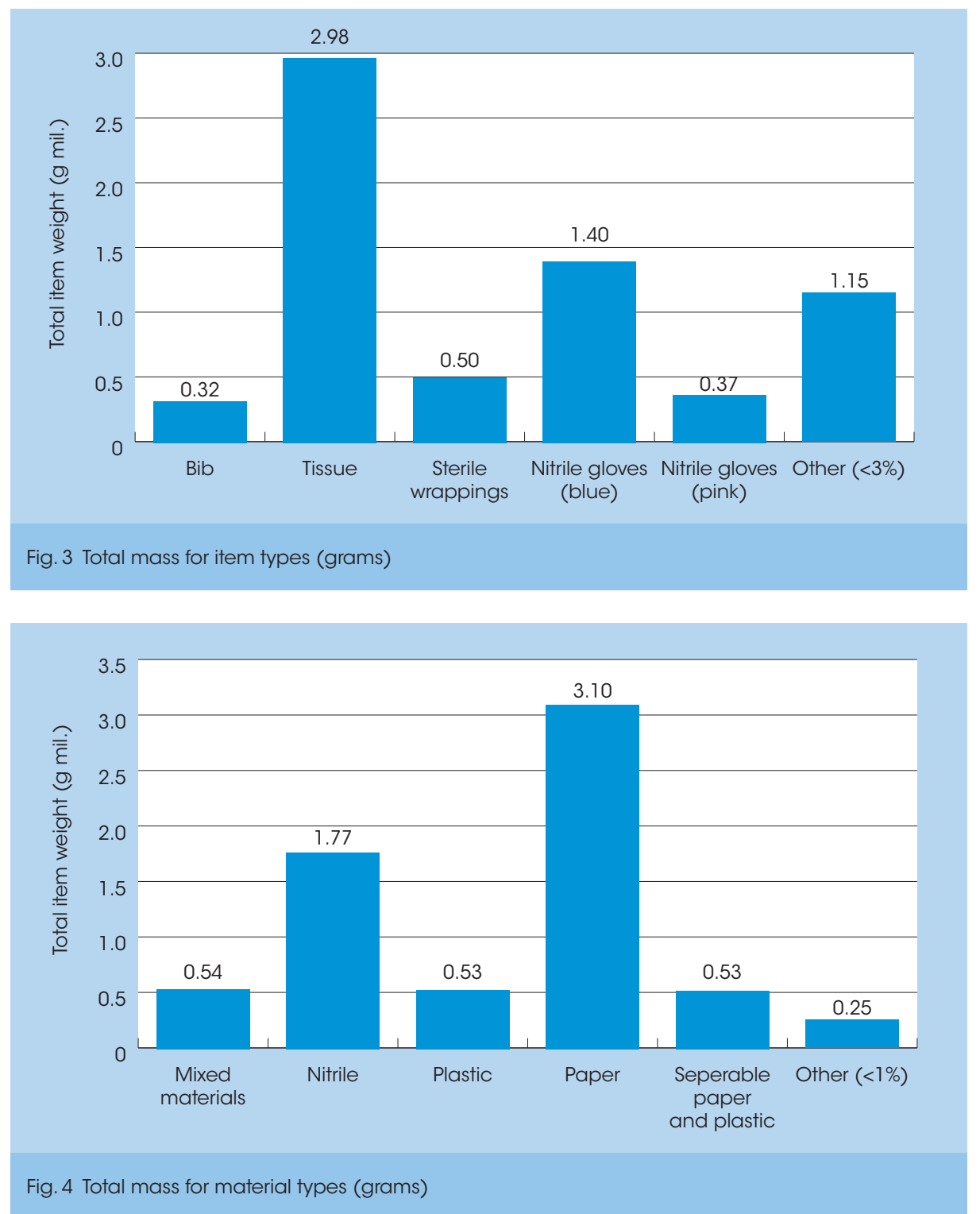

'PAPER TISSUES AND NITRILE GLOVES WERE THE

\section{TWO MOST COMMONLY DISPOSED OF ITEM AND}

\section{MATERIAL TYPES DURING CLINIC SESSIONS.}

At $99 \%$ significance level, the mass of the non-recyclable waste (mass of all other clinical waste items excluding sterile wrapping) have a positive linear relationship to the total mass of the clinical waste bags. This shows that an increase in the total mass of dental clinical waste will result in an increase in the weight of non-recyclable waste. In order to explore the potential GHG savings we conducted further analysis of the data related to sterile wrapping. GHG conversion factors for waste disposal were obtained from the 2011 Guidelines to Defra/ DECC's GHG Conversion Factors for Company Reporting (Table 9d). ${ }^{14}$ The GHG for incineration of clinical waste was taken as $1,833 \mathrm{~kg}$ CO2e emitted per tonne of waste. This is a lifecycle conversion factor accounting for the entire product cycle from material extraction to final disposal. Defra emissions factors for incineration do not specifically account for clinical waste, which is commonly undertaken at higher temperatures. To reflect the increased emissions that are likely to result from the incineration of clinical waste, the highest available emissions factor for incineration was applied. In this audit we have about $5 \mathrm{~kg}$ per week of sterile wrapping $=0.005$ tonnes, resulting in the following calculations: 
- GHG emissions from using and disposing of sterile wrapping as clinical waste per week: 0.005 tonnes $\times 1,833 \mathrm{~kg}$ CO2e per tonne $=9.165 \mathrm{~kg} \mathrm{CO} 2 \mathrm{e}$

- GHG emissions from using and disposing of sterile wrapping as clinical waste per year: $9.165 \mathrm{~kg}$ CO2e per week $\times 52$ weeks $=476.58 \mathrm{~kg} \mathrm{CO} 2 \mathrm{e}$

- GHG emissions for using and disposing of sterile wrapping as recycled waste per week: $0.005 \times 302 \mathrm{~kg} \mathrm{CO} 2$ per tonnes = $1.51 \mathrm{~kg}$ CO2e per week

- GHG emissions from using and disposing of sterile wrapping as recycled waste per year: $1.51 \mathrm{~kg}$ CO2e per week $\times 52=78.52$ $\mathrm{kg} \mathrm{CO} 2 \mathrm{e}$ per year

- GHG savings per year are: $476.58 \mathrm{~kg} \mathrm{CO} 2 \mathrm{e}$ - $(78.52 \mathrm{~kg} \mathrm{CO} 2 \mathrm{e})=555.1 \mathrm{~kg} \mathrm{CO} 2 \mathrm{e}$

- GHG savings per year: 0.5551 tonne CO2e savings per year.

These calculations are based on the waste in the dental practice we audited and the fact that this waste stream is always sent for incineration.

\section{DISCUSSION}

The three Rs (reduce, reuse, recycle) are commonly referred to in managing environmental sustainability. This tends to be given fairly low priority within NHS dental practices, where the focus is predominantly on patient safety, NHS targets and financial stability. Environmental sustainability in dentistry is challenging, and certainly became all the more so following the introduction of revised infection control guidelines in 2009 (HTM 01-05). ${ }^{18}$ The guidelines encourage single use instruments, materials and consumables and reuse is discouraged wherever possible. Sterile wrapping and storage of instruments is advocated, which has had an impact on the amount of plastic and paper disposed of through the increased use of sterilisation bags.

It is difficult to argue against implementation of best practice infection control guidelines if this results in improved patient care. However, the increased use of plastic and paper wrapping is considerable and this has led to increased production of waste and cost. The practice in which this study was conducted incurred a $58 \%$ increase in waste management costs over a four-year period following the introduction of HTM 0105. ${ }^{18}$ Reuse of materials and instruments may have limited potential in view of safety concerns, and the focus must therefore be on reduce and recycle.

Holland identified waste management as an aspect of dental practice for which it would be worth developing practice-based eco guidelines in an attempt to 'save money and minimise impact on the environment. ${ }^{20}$ In discussions with waste management organisations she acknowledged that 'poor waste segregation was an issue. This has also been recognised in the NHS and longterm care sites studied by Manzi et al. ${ }^{19}$ However, in this feasibility study, although some items were wrongly segregated, the majority of waste contained tissues, sterile packaging and gloves used in treatment, and was appropriately disposed of. We therefore concluded that those items appropriately discarded need to be reduced to enable both financial and environmental savings.

The British Medical Association (BMA) has also begun to raise awareness about climate change and the need to manage resources more efficiently. In the report 'Doctors taking action on climate change, ${ }^{21}$ the BMA looked to its own premises and identified areas where it can reduce carbon emissions, serving as an example to doctors to enable changes in practice, for example, in terms of the amount of waste produced. reducing costs by $4 \%$ year on year.

A recent report by the Academy of Royal Medical Colleges ${ }^{22}$ recognised the need for clinicians to be innovative in order to tackle the huge financial challenges we are facing. The report identified a range of behaviours to achieve this, among which were highlighted the need for a 'change in culture - where doctors resolve to eradicate waste.

To our knowledge, GHG and efficiency savings through waste reduction has not been explored within NHS dentistry. The recycling of wrapping used on sterile equipment would probably be the easiest change to implement which could result in considerable waste savings. Based on our results, the financial efficiency savings would be relatively modest due to the significant charges for removal of domestic waste and the practical difficulties in recycling commercial paper and plastic. It is questionable whether small projected savings for a six surgery practice would be sufficient incentive to influence change. This does not take into consideration a potential reduction in glove and tissue use which would also result in considerable waste reductions and

\section{STIERIUE WRAPPING AND STORAGE OF}

\section{INSTRUMENTS IS ADVOCATED, WHICH HAS HAD}

\section{AN IMIPACT ON THE AMOUNT OF PLASTIC}

\section{AND PAPER DISPOSED OF...}

The collection of data from a greater range of dental practices and over a greater period of time would provide a more representative data set. Using detailed data about the waste composition it would also be possible to provide more accurate estimations of dental waste production across the country and estimate cost and carbon footprint figures for any size and type of dental practice. This information could then be used to inform strategic planning for the reduction of the cost and the carbon footprint associated with dental activities and monitor changes over time.

Healthcare is under increasing pressure in terms of demands on services and the spiralling cost of providing care to an ageing population. The need to maximise efficiency has been a key feature of recent healthcare reforms with $£ 20$ billion worth of efficiency savings targeted over the last four years in the NHS. Dentistry has not been immune to these efficiency savings and has been tasked with equi valent cost savings. Our GHG savings are tentative, and this approach needs further development with larger data sets in order to determine suitable strategies to achieve both reduction of the GHG contribution of dental practices and make financial savings without compromising practices and care.

\section{CONCLUSIONS}

In a recent article for the British Dental Journal ${ }^{20}$ Caroline Holland asks 'can a dental practice go green and increase profits?' She concludes that it is 'possible to operate an ecofriendly practice and make a difference to the bottom line.

Holland's opinion, and the system changes recommended by the BMA and the ARMC are recent, but mark a change in attitude towards sustainable practice in clinical care.

There are significant benefits in reducing waste production within the NHS, both in terms of cost and the impact on the environment. The data from our study 
would appear to support the view that it is possible to reduce carbon emissions and increase profitability, although this is likely to require a degree of reorganisation within the practice. Successful implementation of an environmentally sustainable approach to waste management will be dependent on the practicalities involved and the financial incentives for adopting such practices. It is therefore unlikely that significant change will be affected without the influence of government.

\section{STUDY LIMITATIONS}

This feasibility study was carried out in one dental practice so the data must be treated with caution and should not be generalised. However, the study achieved its aim of providing valuable data for a larger study to further explore the findings. The waste audit only included $9 \%$ of the clinical waste in a specific time-frame and didn't include domestic waste or observations of practice.

\section{Benefits to NHS dentistry:}

- Reduction of NHS carbon emissions through reduce, re-use and recycle approaches

- Income generation from viewing waste as resource/recycling

- Reduced waste management costs

- More data is required, but this approach has the potential to inform strategic planning in dentistry.

\section{Benefits to patients}

- Potential efficiency savings within NHS dentistry

- Supports greater choice for patients who are concerned about sustainability and the impact of healthcare on the environment

- Limiting the environmental burden of dentistry will have a positive impact on patients' general health and wellbeing (for example, reduced respiratory disease, allergies etc).

We would like to thank the Institute for Sustainability Solutions Research at Plymouth University for funding this study, and staff in the practice for their time, patience and support during data collection.

1. Mayor S. NHS should bring in measures to reduce its carbon footprint, BMA says. $\mathrm{Br}$ Med J 2008; 336: 740.

2. NHSSDU. Saving Carbon Improving Health. NHS Carbon Reduction Strategy for England. Cambridge: National Health Service Sustainable Development Unit, 2009.
3. Naylor, C, Appleby J. Sustainable health and social care: connecting environmental and financial performance. The King's Fund, 2012. Available online at http:// www.sduhealth.org.uk/documents/R_ and_D_Kings_Fund_Sus_Health_and_ social_care.pdf (accessed January 2016).

4. Health Care Without Harm. Available online at http://www.noharm.org (accessed January 2016).

5. KPMG. Care in a changing world. Challenges and opportunities for sustainable health care. KPMG International, 2012. Available online at https://www.kpmg.com/Global/en/ IssuesAndInsights/ArticlesPublications/ care-in-a-changing-world/Documents/ challenges-opportunities-sustainablehealthcare-v1.pdf.

6. Tudor T, Barr S, Gilg A. A tale of two locational settings: is there a link between pro-environmental behaviour at work and at home? Loc Env 2007; 12: 409-422. .

7. Tudor T, Barr S, Gilg A. Strategies for improving recycling behaviour within the Cornwall National Health Service (NHS) in the UK. Waste Manag Res 2007; 25: 510-516.

8. Tudor T, Barr S, Gilg A. A novel conceptual framework for examining environmental behaviour in large organizations: a case study of the Cornwall National Health Service (NHS) in the United Kingdom. Env Behav 2008; 40: 426-450.

9. Grose J, Bennallick M, Nichols A, Pahl S, Richardson J. Facilitating sustainable waste management behaviours within the health sector: a case study of the National Health Service (NHS) in Southwest England UK. Sustainability 2012; 4: 630-642.

10. Manzi S, Nichols A, Pahl S, Richardson J, Bennallick M, Grose J. How do they manage it? An observational study of health and social care waste management. Psychology and Health 28 (Special Issue, Suppl.1) 2013; pp 262 (meeting abstract).

11. Grose J, Richardson J. Raw materials risk in healthcare supply chains. WRAP. 2012. Available online at http://www.wrap. org.uk/content/report-raw-materialsrisk-healthcare-supply-chains (accessed January 2016).

12. Grose, J, Richardson J. Managing a sustainable, low carbon supply chain in the English National Health Service: The views of senior managers, J Health Serv Res Pol 2013; 18: 83-89.

13. Grose J, Richardson J. Strategies to identify future shortages due to interruptions in the healthcare procurement supply chain: a method from the English National Health Service. J Health Serv Res Pol Pract 2013; 502: 172.

14.DEFRA. Guidelines to Defra / DECC's GHG conversion factors for company reporting: methodology paper for emission factors. London: Department of Energy and Climate Change, 2011. Available online at https://www.gov.uk/government/ uploads/system/uploads/attachment_data/ file/69314/pb13625-emission-factormethodology-paper-110905.pdf (accessed January 2016).

15. NHSDU. Sustainable development strategy 2013-16. NHS Supply Chain. 2013.

Available online at http://www.sduhealth. org.uk/documents/SDMP/SDMP_NHS_ Supply_Chain_2013-2016_Final.pdf (accessed January 2016)

16. Nasser M. Evidence summary: can plastics used in dentistry act as an environmental pollutant? Can we avoid the use of plastics in dental practice? Br Dent J 2012; 212: 89-91.

17. Farmer G M, Stankiewicz N, Michael B, Wojcik A, Lim Y, Ivkovic. Audit of waste collected over 1 week from ten dental practices. A pilot study. Aust Dent J 1997; 42: 114-117.

18. Department of Health. Decontamination: Health Technical Memorandum 01-05: Decontamination in primary care dental practices. Department of Health, 2013. Available online at https://www.gov.uk/ government/uploads/system/uploads/ attachment_data/file/170689/HTM_0105_2013.pdf (accessed January 2016).

19. Manzi S, Mukonoweshuro R, Nichols A. An evidence based computational programme for the simulation, estimation and reduction of health and social care waste. International Association People Environment studies, 2014; pp 128-129 (conference abstract).

20. Holland C. Greening up the bottom line. Br Dent J 2014; 217: 10-11.

21. BMA. Doctors taking action on climate change. BMA Board of Science. (accessed January 2016) Available online at http://www.bma.org.uk/-/media/ files/pdfs/working\%20for\%20change/ doctorstakingactiononclimatechange.pdf (accessed January 2016).

22. ARC. Facing the future: Sustainability for the Medical Royal Colleges. London: Academy of Royal Medical Colleges, 2014. Available online at http://www.aomrc. org.uk/doc_download/9790-medicalroyal-colleges-sustainability-guide.html (accessed January 2016)

bdjteam201680 